\title{
Sennoside Yields in Tinnevelly Senna Affected by Deflowering and Leaf Maturity
}

\section{H.H. Ratnayaka ${ }^{1}$, B. Meurer-Grimes ${ }^{2}$, and D. Kincaid Department of Biological Sciences, Lehman College and the Graduate School of the City University of New York, 250 Bedford Park Boulevard West, Bronx, NY 10468}

Additional index words. sennosides, agronomic practices, photosynthesis, secondary metabolism

\begin{abstract}
Manual deflowering and leaf maturity were evaluated for effect on the yields of the bioactive sennosides A and B in Tinnevelly senna (Cassia angustifolia Vahl). Deflowering increased sennoside $A$ and $B$ concentration (percent dry weight) in leaves by $25 \%$, the total leaf dry mass by $63 \%$, and the harvest index by $22 \%$, with the result that the sennoside A and B yield (grams) per plant doubled in response to deflowering. During the same time, net photosynthesis remained consistently lower in the deflowered plants. Youngest leaves had the greatest sennoside A and B concentration. A clone raised from cuttings of one seedling had lower sennoside $A: B$ ratio than the plants raised from the seedlings. Although crop type and possibly environmental conditions influenced the sennoside A:B ratio, deflowering and leaf maturity had no effect. The sennoside $A$ and B concentrations in the dried leaves of deflowered plants harvested in 1.5-hour intervals appeared to increase during the course of the day. Deflowering, harvesting of young leaves, and harvesting time of day constitute promising component technologies for field investigations.
\end{abstract}

Tinnevelly senna [Cassia angustifolia is synonymous with Senna alexandrina Mill., according to Irwin and Barneby (1982)] is used worldwide as a natural laxative and is included in pharmacopeias of the United States, Germany, United Kingdom, India, and other countries (Al-Dakan et al., 1995; Bown, 1995; Wichtl, 1997). Sennoside A and B (stereoisomers of dihydrodianthrone glucosides) contribute to more than $80 \%$ of the biological activity of senna (Stoll and Becker, 1950; Stuppner and Sturm, 1996; see Fig. 1 for structural formula of sennoside A). Sennosides are being increasingly used in many laxative preparations marketed in the United States. Sennosides are absent in the fresh plant material and form only during postharvest drying (Atzorn et al., 1981). With a higher sennoside concentration than the pods (Atzorn et al., 1981), dried leaflets are the main tissue used in herbal medicine and the pharmaceutical industry. With the exception of India, however, senna is not yet produced commercially as a key cropping component. Our on-farm

Received for publication 22 Jan. 2001. Accepted for publication 15 Feb. 2002. We are grateful to Lehman College and Graduate School of City Univ. of New York for financial assistance. We thank David Cain, Dept. of Biological Sciences, Lehman College, for maintaining the glasshouse facilities.

${ }^{1}$ Current address: Dept. of Entomology, Plant Pathology, and Weed Science, Skeen Hall, New Mexico State Univ., Las Cruces, NM 88003.

${ }^{2}$ Current address: AMRAD Discovery Technologies Pty. Ltd., 576 Swan St., Richmond, VIC 3121, Australia. observational trials in the dry zone of Sri Lanka showed that senna can be successfully established in the dry season on alfisols, if the residual moisture from the previous wet season is used for early crop establishment.

Substantial literature is available on the methods of extraction and quantification of sennosides (Atzorn et al., 1981; Muffat et al., 1986; Stuppner and Sturm, 1996). However, cultural practices that might increase sennoside yields have not been adequately investigated, and contradictory results on the effect of manual deflowering on sennoside concentration have been reported (Lohar et al., 1979; Pareek et al., 1983). We previously reported the effects of drought, foliar nitrogen application, and crop type on leaf sennoside concentration, and on

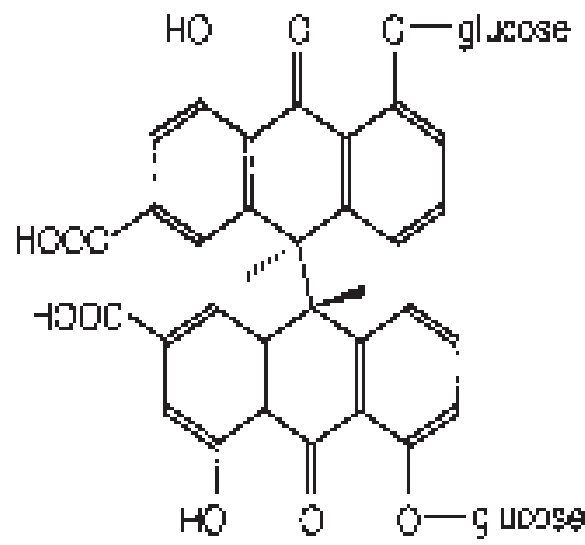

Fig. 1. Structural formula of sennoside A. Sennoside $\mathrm{B}$ is the stereoisomer. total leaf and sennoside yields (Ratnayaka et al., 1998). Evidence was presented that treatments causing lower net photosynthesis $\left(\mathrm{P}_{n e t}\right)$ were associated with high sennoside concentrations in leaves. The main objective of this study was to assess the impact of manual deflowering and leaf maturity on sennoside A and $\mathrm{B}$ concentration of dried senna leaves. This would help to determine if either of these variables may have potential as agronomic practices to be tested in field experiments. $\mathrm{P}_{\text {net }}$ of deflowered and flowered plants also was measured concurrently with the sennoside quantifications of dried leaflets to study the relationship between photosynthetic primary metabolic activity and the production of secondary metabolites as measured by sennoside accumulation. Furthermore, sennoside concentrations of the leaflets harvested from deflowered and flowered plants, at different times of the day, were determined.

\section{Materials and Methods}

Seeds of Cassia angustifolia were obtained from the Ceylon Institute of Scientific and Industrial Research (CISIR), Sri Lanka. In all experiments, leaflets were harvested at $\approx 16: 00$ HR unless mentioned otherwise, and were airdried to constant weight in opaque plastic vials at room temperature.

Leaf maturity. Two groups of plants were produced in a greenhouse, one from seedlings and the other from cuttings, in spring (air temperature, 22 to $28{ }^{\circ} \mathrm{C}$; 14 -h photoperiod with supplemental lighting with fluorescent lamps $\left(350 \mu \mathrm{mol} \cdot \mathrm{m}^{-2} \cdot \mathrm{s}^{-1}\right.$ photosynthetic photon flux). They were grown in 25 -cm-diameter pots containing a soil mixture of 2 top soil : 1 sand : 1 peat (by volume) and a slow-release fertilizer mixture (urea, $1.7 \mathrm{~g}$; triple super phosphate, $1.7 \mathrm{~g} ; \mathrm{KCl}, 1.3 \mathrm{~g}$ per pot). Seedling plants were established by germinating seeds in pots. Cuttings from a 12-month-old deflowered plant were propagated by inserting $6-8$ cm semi-hard wood cuttings into vermiculite. A rooting hormone mix (Dip'N Grow, Astoria Pacific, Warrington, Ore.; IBA, 1\%; NAA, $0.5 \%$ ) was applied to the cuttings before planting. The rooted cuttings were transferred to pots 10 weeks after planting. Both groups of plants were deflowered by removal of flower buds at emergence. They were placed outside the greenhouse in full sun in a completely randomized design 1 month after establishment. All the leaves on one branch of a plant were harvested separately at 15 weeks. Four plants from each group were sampled. To obtain the minimum extractable dry weight from the smaller leaves near the apex, the leaflets from the same nodal position of two plants were combined. The sennoside content was determined and plotted against the leaf nodal position. Leaf 1 was the first fully expanded leaf closest to the apex.

Deflowering. Plants were established by direct seeding in the garden, Lehman College, New York City, on renovated loam soil (organic matter $7.7 \%$, pH 7.1, estimated $\mathrm{N}$ release at $157 \mathrm{~kg} \cdot \mathrm{ha}^{-1}, \mathrm{P}$ at $385 \mathrm{~kg} \cdot \mathrm{ha}^{-1}, \mathrm{~K}$ at 224 $\mathrm{kg} \cdot \mathrm{ha}^{-1}$ ) on 10 June 1995 . Four to five seeds 
were planted per hill at a depth of $2 \mathrm{~cm}$ and a spacing of $40 \times 40 \mathrm{~cm}$, and the plants were thinned to two per hill. Plot size was $2.5 \times 3 \mathrm{~m}$. One plant was kept deflowered by removing the flower buds at emergence, while the other plant was allowed to flower during the whole experiment. Three rates of nitrogen were applied ( $\mathrm{N}$ at 0,40 , or $\left.80 \mathrm{~kg} \cdot \mathrm{ha}^{-1}\right)$, using urea in three designated areas of the experiment in an attempt to simultaneously study the effect of soil-applied $\mathrm{N}$ on sennoside yields. All plants were fertilized with $\mathrm{P}$ at $60 \mathrm{~kg} \cdot \mathrm{ha}^{-1}$ and $\mathrm{K}$ at 80 $\mathrm{kg} \cdot \mathrm{ha}^{-1} \mathrm{using}$ triple super phosphate and $\mathrm{KCl}$. Plants receiving 40 and $80 \mathrm{~kg} \cdot \mathrm{ha}^{-1}$ of nitrogen received 1.37 and $2.8 \mathrm{~g}$ of urea per hill, respectively. All fertilizers were mixed into the soil around hills in two applications at 3 and 6 weeks after seeding. Experimental design was a split plot with three replications, nitrogen rate as main plot, and deflowering as sub-plot. Weeds were removed by hand, and no pesticides were used. Between 8 and 16 weeks after seeding, $\mathrm{P}_{\text {net }}$ was measured weekly using an infrared gas analyzer-based photosynthetic system (model LI 6200; LI-COR, Lincoln, Nebr.). Two terminal leaflets of the second or third fully expanded leaf from the apex were used for measurements. Six leaflets per plant from six plants in each replicate were harvested $8,10,12,14$, and 16 weeks after seeding, for sennoside extraction, during the period of $\mathrm{P}_{\text {net }}$ measurements. These leaflets were selected from the two compound leaves located immediately below the leaves used for $\mathrm{P}_{\text {net }}$ measurements. For the investigations on dry mass allocation, all parts of the 18 plants were dried at $70{ }^{\circ} \mathrm{C}$ to a constant weight at the age of 16 weeks. The harvest index (HI) was computed as the total leaflet weight divided by the total shoot weight.

Sennoside determination. Fifty milligrams of dry leaflets per sample were ground and extracted for determining sennoside content by high performance liquid chromatography (HPLC) as described previously (Ratnayaka et al., 1998). A typical example of HPLC profile with ultraviolet (UV) absorption spectra of sennoside A and B is shown in Fig. 2. Sennoside A and B were identified and quantified using a calibration curve obtained with authentic standards (Carl Roth $\mathrm{GmbH}+\mathrm{Co}$., Germany). Sennoside concentrations were calculated as a percentage of the dry weight of leaflets. The total sennoside content per plant was obtained by multiplying the sennoside content of $50 \mathrm{mg}$ by the total leaflet weights.

Sennoside fluctuations during daytime. Two leaflets per plant from two deflowered and two flowering plants on two hills in a replication were collected starting at 9:00 through 21:00 HR at 1.5-h intervals on a sunny day when the plants were 15 weeks old. All 12 plants sampled received $\mathrm{N}$ at $40 \mathrm{~kg} \cdot \mathrm{ha}^{-1}$. Leaflets from either flowering or deflowered plants were combined for sennoside analysis. Sampling of only two leaflets per plant minimized the stress due to injury caused by continuous leaf removal from the same plants during the course of the day.

Statistical analysis. StatView (Feldman and Gagnon, 1986) and JMP (ver. 2.0.1; SAS
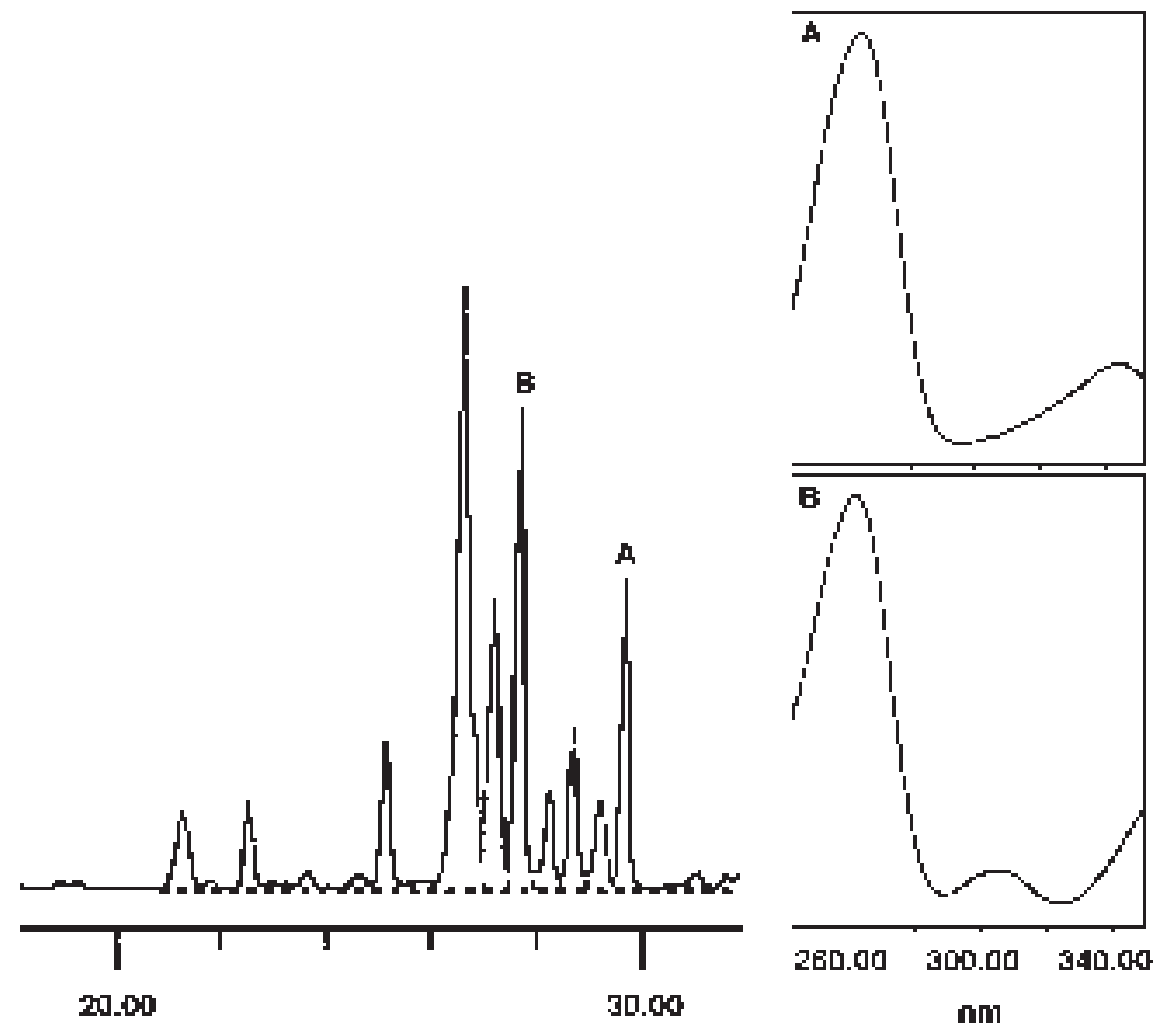

Hivites

Fig. 2. (left) HPLC trace of the leaflet extracts, and (right) UV absorption spectra of sennoside A and B.

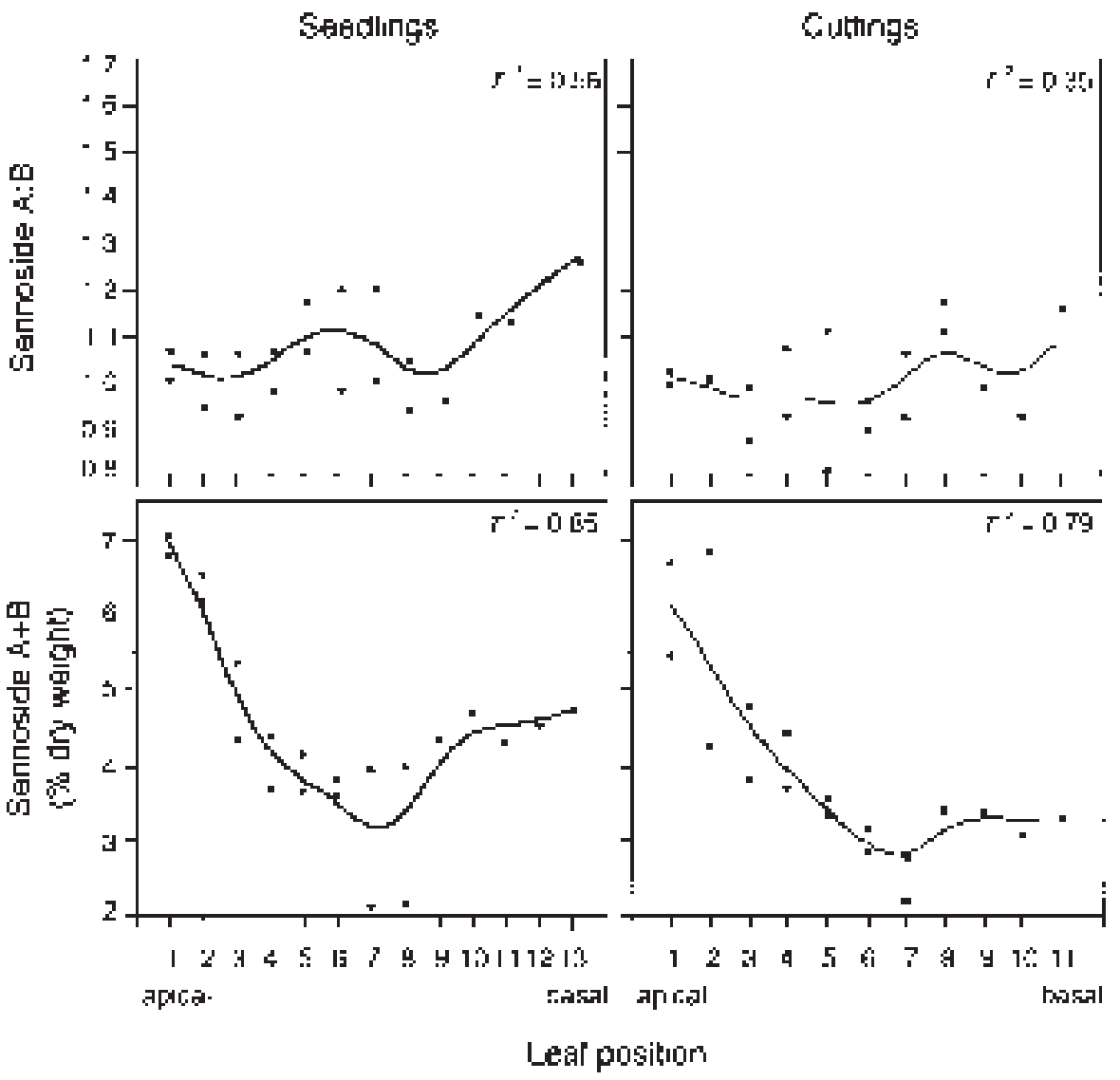

Fig. 3. Effect of leaf maturity on sennoside $A+B$ concentration and sennoside $A: B$ ratio. Leaves are numbered by nodal position starting from the apex downward. The first fully expanded leaf on the branch was taken as the leaf number one. Scatter plots are superimposed with cubic splines. 
Institute) programs on a Macintosh computer were used to analyze the results of response variables, and to determine statistical power and least significant number $\left(\mathrm{LSN}_{0.05}\right)$. $\mathrm{LSN}$ is the minimum sample size that would reduce the variance adequately to produce a significant result. In analysis of variance (ANOVA), $r^{2}$ was computed as the treatment sum of squares divided by the total sum of squares.

\section{Results and Discussion}

Leaf maturity. Concentrations of sennosides A and B were highest in the youngest leaves in both seedlings and cuttings (Fig. 3). In both crop types, the sennoside $\mathrm{A}+\mathrm{B}$ concentration decreased from the youngest leaf to the leaf on the seventh node. Although not quantified according to the nodal position, other authors (Srivastava et al., 1981) have observed higher sennoside yields in younger leaves as compared to mature leaves. Higher sennoside concentration in younger leaves suggests, as in other higher plants containing secondary products, that these (or sennoside precursors) could be involved in some protective functions (Bohnert et al., 1995; Dicke et al., 1990).

The sennoside A:B ratio remained relatively unchanged with increasing leaf maturity. Seedlings had a $9 \%$ higher sennoside A:B ratio $\left(\mathrm{F}_{(1,38)}=5.80, P<0.05, r^{2}=0.13\right)$ and a $18 \%$ higher sennoside $\mathrm{A}+\mathrm{B}$ concentration (statistically nonsignificant) than the plants raised from cuttings. This agrees with our previous findings, although seedlings produced a $33 \%$ greater sennoside $\mathrm{A}+\mathrm{B}$ concentration compared to cuttings (Ratnayaka et al., 1998).

Deflowering. There was no effect of $\mathrm{N}$ level on growth, $\mathrm{P}_{n e t}$, or sennoside content. Very high initial soil N content (see Materials and Methods), which caused all plants including controls to have leaf $\mathrm{N}>4.5 \%$ (data not presented), explains this.

However, sennoside $\mathrm{A}+\mathrm{B}$ concentration, pooled across $3,3-1 / 2$, and 4 months sampling period, was $25 \%$ higher in the deflowered plants than the flowering plants (Fig. $4, P<$ 0.001 ). We also analyzed the data as a logistic regression considering whether sennoside $\mathrm{A}+\mathrm{B}$ concentration is $\leq 3 \%$ or $>3 \%$ as the response variable. Results of this showed that the probability of the sennoside A+B exceeding $3 \%$ is $>70 \%$ in a deflowered plant, while only $<30 \%$ in a flowering plant $(\mathrm{N}=54, P<0.01)$. At the same time, $\mathrm{P}_{n e t}$ was $23 \%$ less in the deflowered than flowering plants (ANOVA, $\mathrm{F}_{(1,898)}=159.9$, $P<0.001, r^{2}=0.15$ with statistical power of nearly one and $\mathrm{LSN}_{0.05}$ of 25). A sharp increase in sennoside $\mathrm{A}$ and $\mathrm{B}$ concentrations occurred in both deflowered and flowering plants after 3 months of age, with concentrations peaking at 36 and $30 \mathrm{mg} \cdot \mathrm{g}^{-1}$ at $3-1 / 2$ months, respectively. Simultaneously, a steady decrease in $\mathrm{P}_{n e t}$ was observed. This appears to be an age- or possibly weather-related response. The sennoside $A: B$ ratio was not influenced by deflowering, but was $>1.0$ up to the age of 3 months and fell to $<0.45$ after $3-1 / 2$ months. This change was due to both an increase in sennoside B and a decrease in sennoside A, and coincided with the onset of cold weather in

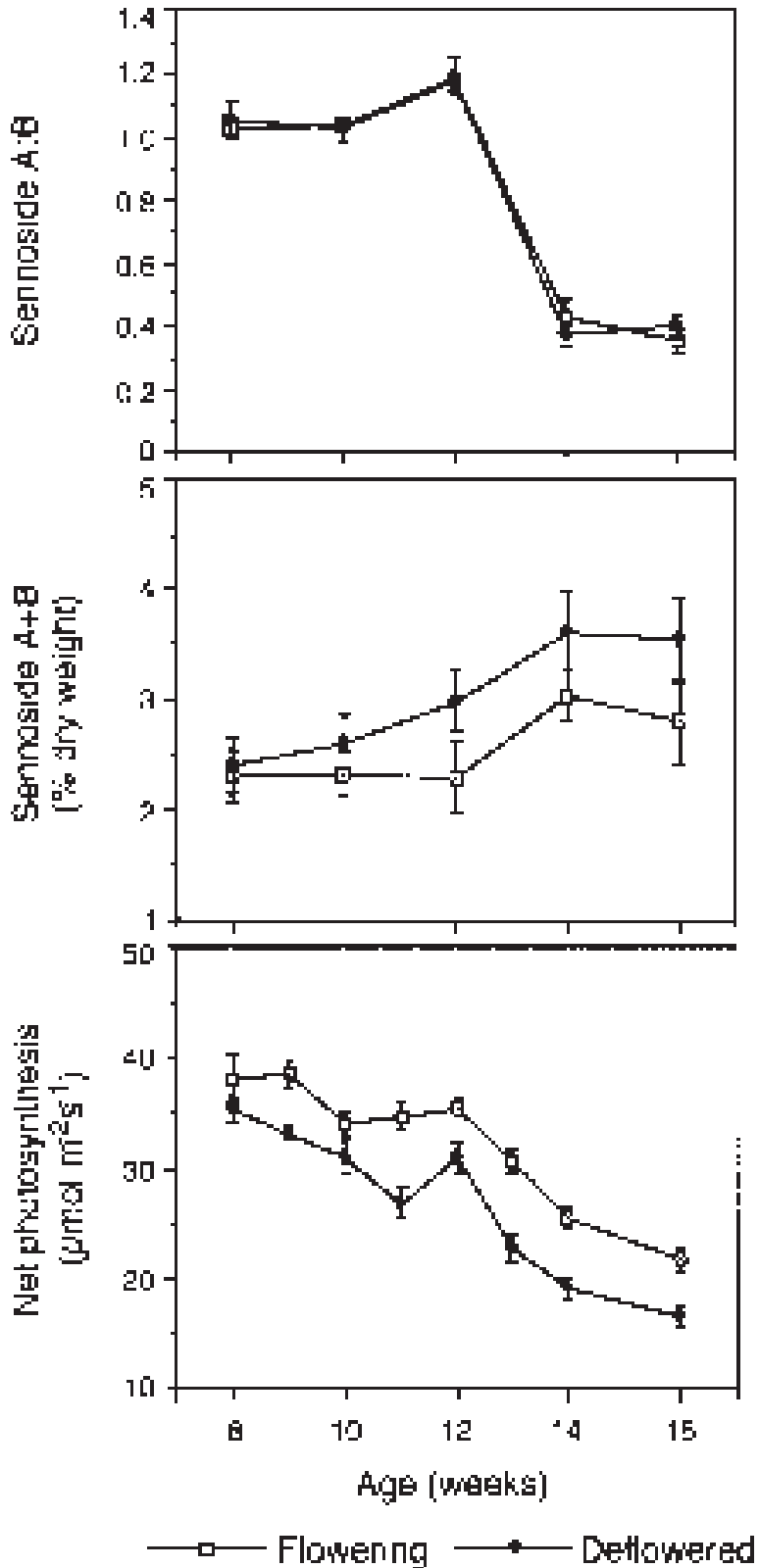

Fig. 4. Effect of deflowering on sennoside A:B ratio, $\mathrm{A}+\mathrm{B}$ concentration, and net photosynthesis during plant development. Error bars represent $95 \%$ confidence interval of the mean.

late September. Average weekly ambient air temperature dropped from 33.2 to $27.7^{\circ} \mathrm{C}$ at this time (data not presented).

Considering the total yield of sennoside $\mathrm{A}+\mathrm{B}$ per plant, deflowered plants produced $\approx 100 \%$ more sennoside $A+B$ than the flowering plants $(0.56 \mathrm{~g}$ per deflowered plant vs. 0.27 g per flowering plant, Fig. 5). This was due to a greater leaflet dry mass $(63 \%$ increase by deflowering), in addition to the higher sennoside concentration. Furthermore, deflowered plants partitioned more dry mass into the leaves than the flowering plants as shown by a $22 \%$ greater HI (Table 1).

Lohar et al. (1979) reported that the leaf sennoside concentration decreased with the onset of flowering and fruiting. On the contrary, Pareek et al. (1983) observed that the removal of flowers and flower buds between 45 and $60 \mathrm{~d}$ after sowing resulted in slightly decreased sennoside concentration in leaves.
In our deflowering experiment, however, flower buds were removed at emergence, from 5 weeks after seeding through the end of the experiment, and this resulted in a significant increase in sennoside concentration.

After 16 weeks, the mean weight of leaflets plus pods was $23 \%$ less in a flowering and fruiting plant than the mean weight of leaflets only in a deflowered plant (Table 1). Sennoside concentrations in organs other than leaves, flowers, and pods are negligible (Atzorn et al., 1981). This suggests that a positive correlation exists between the sennoside concentration in leaves and the total size of the sennoside sink, e.g., the total dry mass comprised of leaves only, or leaves plus pods. In our study, only $8 \%$ of the total dry mass was partitioned into pods in the flowering and fruiting plants. This resulted from the drop of late flowers and early pods triggered by the onset of cold weather in autumn. Therefore, in these plants, the 
sennoside sink was reduced, combined with the loss of sennosides in the dropped tissues, and this may be a cause of the reduced sennoside levels in the flowering plants.

Furthermore, dried younger leaves are richer in sennosides than the mature leaves. Defloration promoted continuous leaf production, as evident in leaf biomass (Table 1). Therefore, deflowered plants have a higher proportion of younger leaves than flowering plants. This further explains the greater sennoside content in the deflowered plants than the flowering plants.

Daytime fluctuations of sennosides. Fluctuations of sennoside A and B were observed during daytime in both flowering and deflowered plants, but they appeared to follow different patterns. The sennoside A:B ratio and the sennoside $\mathrm{A}+\mathrm{B}$ concentration increased toward the evening in deflowered plants but slightly decreased in flowering plants (Fig. 6). In another experiment with potted deflowered plants raised from seedlings, cuttings, and ratoons outside the greenhouse, $\mathrm{P}_{n e t}$ gradually declined during the course of the day from 8:00 to $17: 30 \mathrm{HR}$ in all plants (data not presented). Thus, sennoside $\mathrm{A}+\mathrm{B}$ concentration in deflowered plants appears to follows an inverse relationship with $\mathrm{P}_{\text {net }}$. Daytime patterns of sennoside $\mathrm{A}+\mathrm{B}$ accumulation in the flowering and deflowered plants, and possible interaction effect between climatic variability and the harvesting time of day on sennoside yield warrant further investigation.

Sennoside metabolism. Atzorn et al.,(1981) reported that the sennosides are absent in the fresh plant material of senna. They argued that sennosides may not form solely from 8glucosidorheinanthrone, the supposed monomeric precursor, because this metabolite is present in similar concentrations in both fresh and dry leaves (Atzorn et al., 1981). The results presented in this paper and our previous findings (Ratnayaka et al., 1998) indicate that the sennoside $\mathrm{A}: \mathrm{B}$ ratio appears to vary with both external environmental and plant physiological conditions. For example, plants grown in the greenhouse generally showed a mean sennoside A:B ratio of close to 1.0. Plants grown outdoors (deflowering experiment) showed a similar sennoside A:B ratio but only up to the age of 3 months. Later, this ratio dropped sharply to $<0.45$ due to both an increase in sennoside B and a decrease in sennoside A levels. This may suggest interconversion of the two compounds or their conversion to other intermediary metabolites of the sennoside synthetic pathway. The sharp drop in the sennoside A:B ratio in the plants grown outdoors could be possibly attributed to the reduced ambient air temperatures that set in after the plants were 3 months old. Thus, precursors of sennoside A and B may be influenced differently by changing environmental or plant physiological states. Similar environmental effects on other secondary metabolites are well documented (Bohnert et al., 1995; Harborne, 1993; Taiz and Zeiger, 1998).

Furthermore, the patterns of $\mathrm{P}_{n e t}$ and sennoside concentrations indicate that the physiological conditions associated with flow-

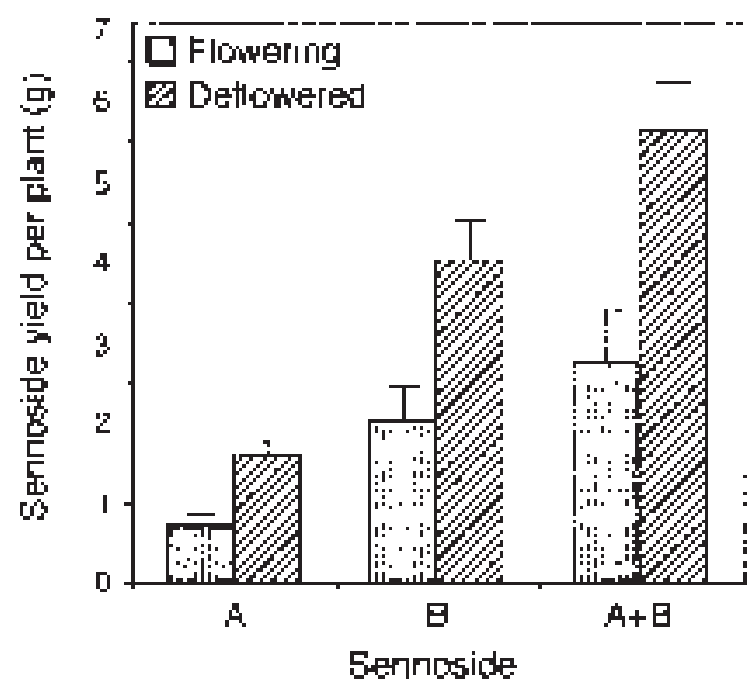

Fig. 5. Effect of deflowering on sennoside A, B and A+B yields per plant. Data are pooled across 3, 3-1/2, and 4 months of age. Error bars are $95 \%$ confidence interval of the mean.

Table 1. Yield of leaflets and pods, and harvest index (HI), of deflowered and flowering plants of senna at 4 months after seeding. Means with \pm sE.

\begin{tabular}{lccc}
\hline $\begin{array}{l}\text { Experimental } \\
\text { treatment }\end{array}$ & $\begin{array}{c}\text { Leaflet } \\
\text { dry mass }(\mathrm{g})\end{array}$ & $\begin{array}{c}\text { Pod } \\
\text { dry mass }(\mathrm{g})\end{array}$ & $\mathrm{HI}^{\mathrm{z}}$ \\
\hline Deflowered & $15.98 \pm 1.0^{* * * *}$ & --- & $0.44 \pm 0.0^{* * * *}$ \\
Flowering & $9.79 \pm 0.8$ & $2.50 \pm 0.3$ & $0.36 \pm 0.0$ \\
\hline
\end{tabular}

${ }^{2}$ Harvest index is dry mass of leaflets divided by dry mass of total shoot (aboveground parts).

${ }^{* * * *}$ Significantly greater than the flowering mean at $P<0.001$.
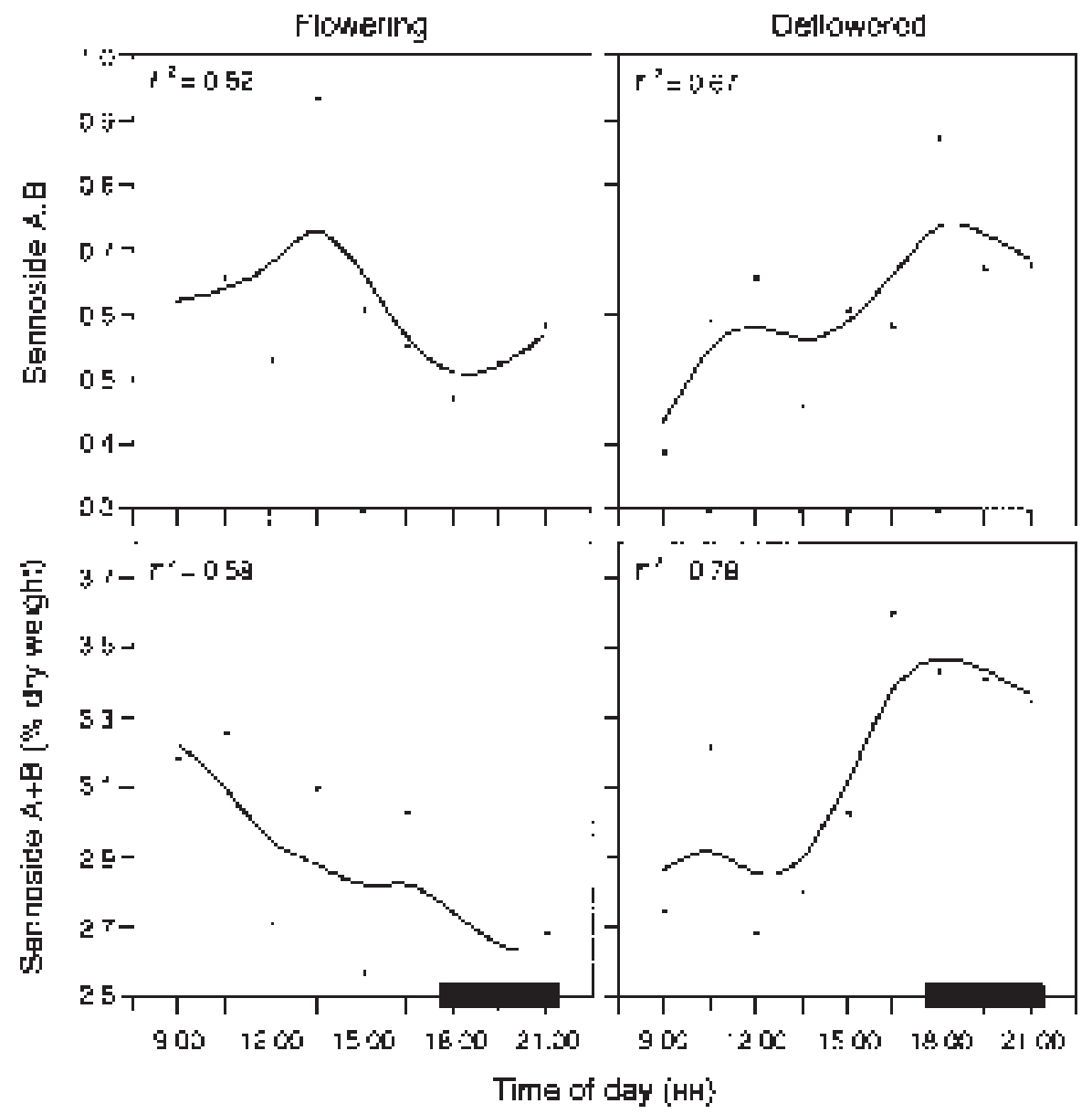

Fig. 6. Daytime fluctuations of the ratio of sennoside A to sennoside B, and sennoside A+B concentration in the dried leaves of flowering and deflowered plants. Scatter plots are superimposed with cubic splines. Black bar on $\mathrm{X}$ axis indicates nighttime. 
ering influence both the secondary metabolism of sennoside precursors and the primary metabolism of $\mathrm{P}_{n e t}$. The inverse relationship between the rate of $\mathrm{P}_{n e t}$ and sennoside concentration agrees with our previous findings that nitrogen and moisture stress enhanced leaf sennoside $\mathrm{A}$ and $\mathrm{B}$ concentration, and reduced $\mathrm{P}_{n e t}$ (Ratnayaka et al., 1998).

Conclusions. Deflowering and harvesting of young leaves offer promise in agricultural efforts to increase the sennoside yield in Tinnevelly senna. Therefore, these treatments should be considered for further field research. Such studies should evaluate harvesting of young leaves and deflowering performed together, and assess their financial benefit, because both these practices are costly and timeconsuming. Based on our present findings, coppicing (pruning apical foliage) at regular intervals appears to be a promising component technology, because it would stimulate growth of new shoots with young leaves and would allow continuous harvesting.

\section{Literature Cited}

Al-Dakan, A.A., M. Al-Tuffail, and M.A. Hannan. 1995. Cassia senna inhibits mutagenic activities of benzo[a]-pyrene, aflatoxin $\mathrm{B}_{1}$, gamma and methyl methanesulfonate. Pharmacol. Toxicol. 77:288-292.

Atzorn, R., E.W. Weiler, and M.H. Zenk. 1981. Formation and distribution of sennosides in Cassia angustifolia, as determined by a sensitive and specific radioimmunoassay. Planta Medica 41:1-14.

Bohnert, H.J., D.E. Nelson, and R.G. Jensen. 1995. Adaptations to environmental stress. Plant Cell 7:1099-1111.

Bown, D. 1995. Encyclopedia of herbs and their uses. Herb Soc. America. Dorling Kindersley, New York.

Dicke, M., M.W. Sabelis, J. Takabayashi, J. Bruin, and M.A. Posthumus. 1990. Plant strategies of manipulating predator-prey interactions through allelochemicals-Prospects for application in pest-control. J. Chem. Ecol. 16:30913118.

Feldman, D.S., Jr. and J. Gagnon. 1986. StatView. Abacus Inc., USA.

Harborne, J.B. 1993. Introduction to ecological biochemistry. 4th ed. Academic, San Diego.

Irwin, H.S. and R.C. Barneby. 1982. American Cassiinae: A synoptical revision of Leguminosae tribe Cassieae subtribe Cassiinae in the New World. Mem. N.Y. Bot. Gard. 35:481-482.

Lohar, D.R., R.K. Bhatia, S.P. Garg, and D.D. Chawan. 1979. Seasonal variation in the content of sennoside in senna leaves. Pharmaceutisch
Weekblad Scientific Ed. 1:206-208.

Muffat, F., P. Bernard, and J.F. Sabot. 1986. Determination of sennosides A and B in senna extracts by high performance liquid chromatography. J. Chromat. 369:261-264.

Pareek, S.K., V.K. Srivastava, M.L. Maheshwari, S. Mandal, and R. Gupta. 1983. Investigation in agronomic parameters of senna (Cassia angustifolia Vahl) as grown in north-western India. Intl. J. Trop. Agr. 1:139-144.

Ratnayaka, H.H., B. Meurer-Grimes, and D.T Kincaid. 1998. Increasing sennoside yields in Tinnevelly senna (Cassia angustifolia) I: Effects of drought, foliar nitrogen spray and crop type. Planta Medica 64:438-442.

Srivastava, V.K., M.L. Maheshwari, S. Sing, and R. Gupta. 1981. Dynamics and localization of anthracene compounds during growth of senna plants, Cassia angustifolia Vahl. Herba Hungarica 20:1-2.

Stoll, A. and B. Becker. 1950. Sennoside A and B, the active principles of senna. Fortschritte der Chemie Organischer Naturstoffe 7:248-269.

Stuppner, H. and S. Sturm. 1996. LC-MS and CZE of dianthrones from Cassia angustifolia and acutifolia. Chromatographia 42:697-703.

Taiz, L. and E. Zeiger. 1998. Plant physiology. 2nd ed. Sinauer Assoc., Sunderland, Mass.

Wichtl, M. 1997. Teedrogen und Phytopharmaka. 3rd ed. Wissenschaftliche Verlagsgesellschaft mbH Stuttgart, Germany. 